\title{
CIPARS: A One-Health Approach to Antimicrobial Resistance Surveillance
}

\author{
Anne Deckert ${ }^{\star 1}$, Agnes Agunos ${ }^{1}$, Brent Avery ${ }^{1}$, Carolee Carson ${ }^{1}$, Danielle Daignault ${ }^{2}$, Rita \\ Finley ${ }^{3}$, Sheryl Gow ${ }^{4}$, David Léger ${ }^{1}$, Michael Mulvey ${ }^{5}$, Jane Parmley¹, Richard Reid-Smith ${ }^{1}$ \\ and Rebecca Irwin ${ }^{1}$
}

'Laboratory for Foodborne Zoonoses, Public Health Agency of Canada, Guelph, ON, Canada; '2aboratory for Foodborne Zoonoses, Public Health Agency of Canada, St Hyacinthe, QC, Canada; ${ }^{3}$ Centre for Foodborne, Environmental, and Zoonotic Infectious Diseases, Public Health Agency of Canada, Guelph, ON, Canada; ${ }^{4}$ Laboratory for Foodborne Zoonoses, Public Health Agency of Canada, Saskatoon, SK, Canada; ${ }^{5}$ National Microbiology Laboratory, Public Health Agency of Canada, Winnipeg, MB, Canada

\section{Objective}

The objective of the Canadian Integrated Program for Antimicrobial Resistance Surveillance (CIPARS) is to provide a unified approach to monitor national trends in antimicrobial resistance (AMR) and antimicrobial use (AMU) in humans and animals and to facilitate the assessment of the public health impact of antimicrobial use.

\section{Introduction}

AMR has been identified as a global threat to public health. Resistant bacteria and associated genes can move within and between populations of people and animals, making AMR a very complex and contentious issue. Credible, multi-sectoral surveillance data provide information to promote prudent AMU in hospitals, the community, and agriculture.

\section{Methods}

CIPARS was created through agreements with organizations with useful existing data/isolate sources and the development of active surveillance to fill critical gaps. CIPARS includes active sampling of beef, pork and chicken at farm, abattoir and retail and the submission of clinical Salmonella isolates from human and veterinary cases for AMR testing. AMU data are collected from physicians, hospitals, and pharmacies, veterinary pharmaceutical companies, and pig and chicken producers. A central data repository was developed for laboratory and epidemiological AMR data to standardize and facilitate analysis. AMU data are stored in flat and relational databases. Molecular characterization of targeted isolates provides critical information about the relationship between AMR in human and animal populations.

Broad stakeholder engagement, ensuring the confidentiality of results, and responsiveness to stakeholder feedback were critical to the development and ongoing sustainability of the program. Private industry stakeholders were involved in the development of the program and in ongoing data/isolate collection but are not involved in data analysis or report production. Notification of results prior to publication is essential for both government and private sector participants. Therefore, CIPARS is coordinated by the Public Health Agency of Canada (PHAC) but is based on collaborations with governments (health and agriculture, federal, provincial, local), private industry (veterinarians, livestock producers, and abattoirs), and academia.

\section{Results}

Direct stakeholder engagement has led to action based on surveillance results as well as an increased awareness of AMR. Examples include: the voluntary ban on ceftiofur use in chicken hatcheries in one province based on CIPARS surveillance results from that province and the more recent ban by the chicken industry on the use of very important human antimicrobials for the prevention of disease in broiler chickens. CIPARS maximizes the use of surveillance data by collaborating with other public health initiatives such as the enteric surveillance program FoodNet Canada. CIPARS data are also used in outbreak investigations, post-approval monitoring of veterinary drugs, research, and source attribution.

\section{Conclusions}

By standardizing methods of sample collection, laboratory testing, data analysis and reporting, but creating a flexible system of stakeholder involvement unique to each component of CIPARS, the system meets stakeholder needs while providing a holistic understanding of AMR in Canada. By taking a One Health approach and generating data at various points in the food chain, it is possible to investigate potential intervention points as well as to evaluate interventions undertaken by both government and/or private industry.

\section{Keywords}

surveillance; antimicrobial resistance; antimicrobial use; One-Health

\section{References}

Government of Canada. Canadian Integrated Program for Antimicrobial Resistance Surveillance. [Internet]. Ottawa (ON): [updated: $2007 \mathrm{Jul}$ 26; cited: 2014 Sep 3]. Available from: http://www.phac-aspc.gc.ca/ cipars-picra/index-eng.php

Government of Canada. FoodNet Canada. [Internet]. Ottawa (ON): [updated: 2013 Nov 15; cited: 2014 Sep 3]. Available from: http:// www.phac-aspc.gc.ca/foodnetcanada/index-eng.php

Léger D, Deckert,A, Gow S, Agunos A, Reid-Smith R. CIPARS: An approach to building collaboration for a voluntary farm surveillance framework. Epidémiol. et santé anim. 2011; 59: 348-51

\footnotetext{
*Anne Deckert

E-mail: anne.deckert@phac-aspc.gc.ca
} 